\title{
Las medidas cautelares constitucionales y su desarrollo en la jurisprudencia de la Corte Constitucional del Ecuador.
}

\author{
Constitutional precautionary measures and \\ its development in jurisprudence of the \\ Constitutional Court of Ecuador
}

\begin{abstract}
PhD. Andrés Cervantes Valarezo*
Universidad Pompeu Fabra, España
\end{abstract}

Infomación del Artículo

Original - Ruptura, 2020

Artículo recibido / Received: 23 de septiembre, 2020

Artículo aceptado / Accepted: 19 de noviembre, 2020

\section{Citación}

Cervantes, A. (2020). Las medidas cautelares constitucionales y su desarrollo en la jurisprudencia de la Corte Constitucional del Ecuador. Revista Ruptura de la Asociación Escuela de Derecho de la PUCE. Edición 2020, p. (171-210).

DOI: $10.26807 /$ rr.vi02.23

Resumen: El presente artículo analiza las medidas cautelares constitucionales, como una garantía jurisdiccional de la norma fundamental, desde la perspectiva teórica y jurisprudencial. Estas tienen como objeto la prevención de lesiones de derechos fundamentales o bien cesar una lesión en curso. En el primer caso, se propondrán de forma

* Abogado por la Universidad de Especialidades Espíritu Santo. Máster en Ciencias Jurídicas Avanzadas por la Universidad Pompeu Fabra. Máster en Derecho Constitucional por la Universidad de Valencia. Doctor (PhD) en Derecho con honores (cum laude) por la Universidad Pompeu Fabra. Profesor de Derecho Constitucional en la Universidad de Especialidades Espíritu Santo y en la Universidad Pompeu Fabra. Correo electrónico: andrescervantes@upf.edu 
autónoma y en el segundo deben necesariamente proponerse en conjunto a una garantía jurisdiccional de conocimiento. Los requisitos para ser concedidas son verosimilitud de la petición, la afectación potencial o actual de derechos fundamentales, la concurrencia de un daño irreversible, grave o sistemático y la ausencia manifiesta de causas de improcedencia. Además, se analiza el régimen de recursos de impugnación y la importancia del principio de proporcionalidad al conceder la protección cautelar. El artículo también destaca los principales cambios jurisprudenciales incorporados por la actual formación de la Corte Constitucional del Ecuador en esta materia, estos son, la improcedencia de la acción extraordinaria de protección y de la acción de incumplimiento en casos de autos de medidas cautelares constitucionales.

Palabras clave: Medidas cautelares, proporcionalidad, provisionalidad, procedimiento.

Abstract: The paper analyses the precautionary measures in constitutional law, as a jurisdictional guarantee of the Ecuadorian constitution of 2008 , both from the theoretical and jurisprudential perspective. Precautionary measures are intended to prevent or to cease fundamental rights violations. If the aim is to prevent a foreseeable damage, precautionary measures shall be solicited autonomously and if the objective is to cease and ongoing violation to fundamental rights, precautionary measures must necessarily be proposed along with another constitutional action. The legal requirements for precautionary measures to be granted are the coherence of the facts alleged in the petition, the potential or actual impairment of fundamental rights, the concurrence of an irreversible, serious or systematic damage and the manifest absence of inadmissibility causes as established in the law. In addition, the essay explains the system of appeal and the importance of the principle of proportionality when granting precautionary measures.

Keywords: Precautionary measures, proportionality, temporality, procedure. 


\section{Introducción}

Las medidas cautelares constitucionales son una garantía jurisdiccional de la norma fundamental y por ende de los derechos que esta reconoce a las personas. En esa medida, son también una manifestación procesal del derecho a la tutela judicial efectiva (CRE, 2008 Art.75) que, como ha manifestado la doctrina y recogido la jurisprudencia de la Corte Constitucional del Ecuador, tiene tres momentos procesales: el acceso a un órgano jurisdiccional, la tramitación de la causa conforme las exigencias del debido proceso y que la decisión jurisdiccional dictada sea efectivamente cumplida.

En ese sentido, el objetivo de las medidas cautelares constitucionales es prevenir o cesar una violación de derechos fundamentales producida por la acción u omisión de un particular ${ }^{1} \mathrm{o}$ del poder público. Lo interesante es que el procedimiento presenta notables diferencias respecto del procedimiento civil, por ejemplo. Como muestra de esto, valga señalar, sin ánimo exhaustivo, sino más bien introductorio, el hecho de que en el procedimiento constitucional las medidas cautelares no requieren ningún principio de prueba, como sí es exigible en el procedimiento civil, bastando con la verosimilitud de la petición. Además, en ejercicio de lo que en doctrina se denomina "autonomía procesal", la Corte Constitucional del Ecuador ha ido construyendo el derecho procesal, así, por ejemplo, mientras que la Corte Constitucional cesada admitía la acción de incumplimiento y la acción extraordinaria de protección en autos referentes a medidas cautelares constitucionales, la actual formación lo ha descartado apartándose de aquel precedente jurisprudencial.

1 Como es bien conocido, las constituciones de posguerra, especialmente a raíz de la Ley Fundamental de Bonn de 1949, amplían su eficacia de tal suerte que los derechos no son exigibles solo en las relaciones verticales entre el Estado y la persona sino también entre particulares, como manifestación de la fuerza normativa y total de la constitución en la vida social. A esta doctrina se le conoce, en Alemania, como Drittwirkung dar Grundrechte o, si se prefiere, eficacia horizontal de los derechos fundamentales. Vid. En general, (Valadés, 2011) y (Alexy, 1993). 
Por tanto, el objeto de estudio, las medidas cautelares constitucionales, tiene dos características que merecen resaltarse: 1 . Tiene una regulación procesal específica, que dista del derecho procesal general y se inscribe en la denominada dogmática del derecho procesal constitucional (Ferrer Mac-Gregor \& Fix-Zambrano, 2013); y, 2. Esa regulación procedimental es dinámica y no estática, es decir, es constantemente moldeada por el intérprete autorizado de la constitución (Rodríguez-Patrón, 2001).

\section{Las medidas cautelares: Una aproximación histórica y dogmática}

En la historia del constitucionalismo ecuatoriano, el antecedente inmediato de las medidas procesales constitucionales es el denominado amparo constitucional de la Constitución Política de $1998^{2}$. El artículo 95 del texto constitucional pretérito regulaba esta acción como "preferente y sumaria", para "la adopción de medidas urgentes destinadas a cesar, evitar la comisión o remediar inmediatamente las consecuencias de un acto u omisión ilegítimos de una autoridad pública, que viole o pueda violar cualquier derecho consagrado en la Constitución o en un tratado o convenio internacional vigente, $\mathrm{y}$ que, de modo inminente, amenace con causar un daño grave".

Es cierto, por otro lado, que el amparo jurisdiccional aparece nombrado por vez primera en la Constitución ecuatoriana de 1967, en el artículo 28.5, aunque el texto se limitaba a señalar que las personas tenían el "derecho a demandar el amparo jurisdiccional contra cualquier violación de las garantías constitucionales", pero no detallaba regulación procesal alguna para hacer efectiva la acción judicial. Por decirlo abreviadamente: la concepción del amparo como una acción cautelar constitucional es propia de los desarrollos legislativos de

2 Constitución Política del Ecuador, Decreto Legislativo No. 000. RO/ 1 de 11 de agosto de 1998 . 
$1997^{3}$ y constitucionales de $1998^{4}$ y son, por tanto, el antecedente inmediato de las medidas cautelares que recoge la Constitución de la República de 2008, actualmente vigente (Valle, 2012). Las medidas cautelares como garantía jurisdiccional de los derechos fundamentales tienen asidero en el capítulo tercero, sección primera, del título tercero (garantías constitucionales) de la norma fundamental, específicamente, en el artículo 87 de la CRE ${ }^{5}$. Sirva resaltar aquella obviedad para listar algunas consecuencias normativas importantes derivadas del reconocimiento constitucional de esta institución:

1. Conforme a los artículos 441 y 442 CRE, los procedimientos de enmienda y de reforma parcial de la Constitución no pueden ser aplicados para introducir restricciones a las garantías de los derechos, entre las que se incluye, por supuesto, a la garantía de medidas cautelares constitucionales. Sí, resultaría procedente, en cambio, enmendar la norma fundamental para regular en forma más favorable las garantías jurisdiccionales.

3 La Ley de Control Constitucional de 1997 señalaba en su art. 46: "El recurso de amparo tiene por objeto la tutela judicial efectiva de los derechos consagrados en la Constitución y los consignados en las declaraciones, pactos, convenios y demás instrumentos internacionales vigentes en el Ecuador, frente a cualquier atentado proveniente de acto ilegítimo de autoridad de la administración pública que haya causado, cause o pueda causar un daño inminente, a más de grave e irreparable y se interpondrá para requerir la adopción de medidas urgentes, destinadas a cesar la lesión o evitar el peligro de los bienes protegidos. También podrá ser objeto de amparo la no expedición de un acto o la no ejecución de un hecho, si tales omisiones causaren o puedan causar los efectos señalados en el inciso anterior".

4 Las resoluciones de la Corte Suprema de Justicia de 2001 (R.O. No. 378, de 27 de julio de 2001) y 2002 (R.O. No. 559, 19 de abril de 2002) establecieron un alcance restrictivo del amparo como medida cautelar.

5 La Constitución ecuatoriana reconoce garantías de tres niveles ("Aquéllas consisten en la obligación, a la cual está vinculado el legislador en correspondencia con tales derechos, de establecer una legislación de ejecución: en suma, en la obligación de introducir las garantías primarias y secundarias correlativas a los derechos fundamentales estipulados): normativas, jurisdiccionales y de políticas públicas, inspirada en la teorización del garantismo de Luigi Ferrajoli. Cfr. (Ferrajoli, 2006, p.28). 
2. Para introducir una restricción a la -escueta- regulación que prevé la constitución en materia de medidas cautelares se requeriría entonces del procedimiento más riguroso previsto en la norma fundamental, la Asamblea Constituyente (Art. $444 \mathrm{CRE}$ ).

3. Lo dicho implica, en primer lugar, que el legislador está vedado de suprimir esta garantía de la ley de la materia (LOGJCC) o bien de tornarla impracticable ya que el artículo 84 CRE obliga al legislativo a adecuar "formal y materialmente" las leyes al contenido de la Constitución.

4. En todo caso, la regulación constitucional sobre medidas cautelares es mínima: se reconoce que pueden ser propuestas de forma autónoma o en conjunto a otra garantía jurisdiccional y que su razón de ser es la de prevenir una inminente violación de derechos fundamentales o bien hacerla cesar. Fuera de estos dos límites referentes al procedimiento y al objeto el legislador cuenta con un amplio margen de apreciación para regular la institución, siempre por medio de una ley orgánica (CRE, 2008, art.133.2) puesto que en caso de regularse por ley ordinaria se produciría una inconstitucionalidad por la forma ${ }^{6}$.

5. Conforme reconoce la jurisprudencia de la Corte Constitucional del Ecuador, las medidas cautelares proceden respecto de derechos fundamentales, es decir, tanto en el caso de derechos previstos en la Constitución como respecto aquellos previstos en instrumentos internacionales de derechos humanos. Además, las medidas cautelares tienen siempre un fin preventivo,

6 Aunque debe llamarse la atención sobre el hecho de que el trámite y los requisitos de votación son los mismos tanto para la ley orgánica como para la ley ordinaria. En efecto, el artículo 53 de la Ley Orgánica de la Función Legislativa (LOFL) señala que la expedición, reforma, derogación e interpretación con carácter generalmente obligatorio de leyes orgánicas y ordinarias requieren del voto de la "mayoría absoluta de las y los miembros de la Asamblea Nacional". Esta situación se produce, básicamente, porque la Constitución no diferencia los requisitos de votación y trámite para leyes orgánicas y ordinarias. 
pero nunca reparador y el proceso no es de conocimiento sino, más bien, sumario (CCE. Sentencia No. 66-15-JC/19, 10 de septiembre de 2019, párrs. 19-20).

\section{La legitimación en los procesos cautelares constitucionales}

\subsection{La legitimación activa}

La legitimación en la causa es la titularidad del interés materia del litigio y que debe ser objeto la resolución judicial de medidas cautelares $^{7}$. Y por lo que al demandado se refiere, consiste en la titularidad del interés en litigio. Dicho en otras palabras, el legitimado activo es quién afirma ser titular del derecho fundamental amenazado o lesionado. Recordar este primer concepto básico es útil por dos motivos:

Primero, el "accionante" no es siempre "la persona afectada" (LOGJCC, art.10) y, por ejemplo, el Defensor del Pueblo (LOGJCC, art.9) podría proponer la solicitud de medidas cautelares en relación con terceros. De darse el caso, el juez debe notificar obligatoriamente al afectado que "podrá comparecer en cualquier momento, modificar la demanda, desistir de la acción o deducir los recursos de ley, aunque no haya comparecido antes" (LOGJCC, art.10). Esto es especialmente relevante debido al artículo 27 de la LOGJCC que dispone: "Las medidas cautelares procederán cuando la jueza o juez tenga conocimiento de un hecho por parte de cualquier persona que amenace de modo inminente y grave con violar un derecho o viole un derecho".

Dadas las singularidades de las que se ocupan las medidas cautelares, la ley permite que cualquier persona las solicite en favor de otra. Un ejemplo sencillo: quien requiere beneficiarse de un hábeas corpus

7 En ese sentido, el artículo 9 de la LOGJCC dispone: "Se consideran personas afectadas quienes sean víctimas directas o indirectas de la violación de derechos que puedan demostrar daño". 
por haber sido privado ilegalmente de su libertad no puede proponer por sí mismo la garantía jurisdiccional de conocimiento y tampoco una medida cautelar, como la comunicación inmediata del juez con las autoridades o la visita in loco al detenido. Por ese motivo, la ley faculta a que cualquier tercero pueda solicitar protección cautelar. Pero si el afectado no ratifica las actuaciones del tercero estaremos ante un supuesto de ilegitimidad de personería y eso explica las posibilidades que da la ley en el sentido de modificar o desistir de las medidas cautelares e inclusive interponer extemporáneamente recursos.

Segundo, al tenor de lo dispuesto en el artículo 86.1 de la CRE y el artículo 32 de la LOGJCC, las medidas cautelares pueden ser solicitadas por "cualquier persona". Ello naturalmente incluye a personas físicas y jurídicas de derecho privado pues gozan de derechos fundamentales. Pero esta afirmación merece matices, pues los derechos fundamentales de las personas naturales y de las personas jurídicas de derecho privado no son idénticos, ni en cuanto a número o alcance. La Corte Constitucional del Ecuador ha señalado al respecto que:

Pese a que las personas jurídicas no son titulares de todos los derechos constitucionales fundamentales, sí lo son de aquellos que les correspondan, según su naturaleza social y siempre en atención a la definición constitucional de los derechos de los que se trate (...) (CCE, sentencia No. 068-10-SEP-CC, 09 de diciembre del 2010).

Resulta evidente, por otro lado, que las personas jurídicas no pueden ser titulares de derechos como la libertad personal, el derecho de sufragio activo y pasivo o el derecho al matrimonio. Y esto resulta lógico a pesar de que el artículo 11.2 de la CRE afirme que: "Todas las personas son iguales y gozarán de los mismos derechos, deberes y oportunidades".

Con todo, debemos recordar que también entre personas jurídicas de derecho privado cabe hacer una distinción, al menos, entre aquellas que persiguen fines de lucro y otras que no. Así, por ejemplo, sería razonable extender el derecho a profesar libremente creencias religiosas y actuar conforme a ellas a fundaciones que respondan a un determinado credo. No tendría sentido, por otro lado, extender 
ese mismo derecho a un fideicomiso mercantil o a un sindicato de trabajadores, por ejemplo (Cruz Villalón, 19992, pp.63-83).

¿Pero cómo afecta esta cuestión el análisis sobre las medidas cautelares constitucionales? La respuesta es que, si ex ante un sujeto no puede ser considerado titular de un derecho fundamental, tampoco podría solicitar medidas cautelares para prevenir la prevención de la lesión o el cese del daño, simplemente, porque ese derecho no es predicable de quién lo alega. Pero, sin duda, hay que advertir que esta distinción no es sencilla de trazar pues, como se vio, la Constitución no la hace, pero la impone la lógica y la jurisprudencia constitucional y, además, porque demanda del estudio y argumentación caso por caso.

De este modo, si bien se pueden plantear casos paradigmáticos en los que una persona jurídica de derecho privado no es titular de un derecho constitucional (derecho a la inviolabilidad de la vida o el derecho a contraer matrimonio); también existen casos en los que claramente se puede predicar dicha titularidad (derecho a la libertad de contratación, derecho a la libertad de asociación); y, finalmente, se pueden plantear casos que despierten dudas fundadas sobre la titularidad o falta de esta. Por ejemplo, "el derecho al honor y al buen nombre" que, por cierto, sí se reconoce en nuestro ordenamiento legal para las personas jurídicas titulares de la acción de daño moral en el ámbito civile.

El segundo motivo por el cual es de importancia ahondar en la cuestión de la legitimación activa tiene que ver con la posibilidad de que personas jurídicas de derecho público hagan uso de la garantía jurisdiccional de medidas cautelares, especialmente, si se tiene en cuenta que las personas tienen derechos mientras que el Estado tiene competencias, atribuciones o potestades, es decir, que las garantías jurisdiccionales fueron pensadas para proteger al individuo frente al poder del Estado y no a la inversa.

Sobre este argumento, Díaz Lema (1989) manifiesta que:

8 Art. 2233. Código Civil ecuatoriano. "Cuando el daño moral afecte a las instituciones o personas jurídicas, la citada acción corresponderá a sus representantes”. 
Difícilmente puede el Estado ser titular de derechos fundamentales, porque la misma persona vendría a ser sujeto activo y pasivo de la relación jurídica. ¿Qué sentido tendría que el Estado se protegiera de sí mismo? Pero si se analiza con más detalle, se advierte enseguida que no puede despacharse el asunto con ligereza. La confusión inicial de las posiciones activa y pasiva de esta relación jurídica no tiene por qué existir forzosamente en todos los casos. Al fin y al cabo, existen relaciones jurídicas entre las distintas Administraciones públicas de tipo territorial, así como respecto de sus Organismos autónomos o de la llamada Administración Corporativa. La pluralidad de centros de imputación o de organizaciones dotadas de personalidad jurídica obliga a plantearse la posibilidad de derechos fundamentales de personas jurídico-públicas (p.85).

En efecto, la doctrina en general ha debido aceptar que las personas de derecho público son titulares, al menos, del derecho al debido proceso como exigencia necesaria del orden público. Empero, el argumento de (Díaz Lema, 1989) va más allá y sostiene que ciertas instituciones públicas tienen derechos constitucionales -con todo el rigor del término- que pueden exigirse ante otras instituciones públicas. No se trata entonces de un problema conceptual indisoluble sino más bien de una cuestión contingente: existirán derechos constitucionales de personas jurídicas de derecho público en la medida que la constitución así lo reconozca. Veamos un ejemplo en el artículo 335 de la Constitución ecuatoriana:

Se reconoce a las universidades y escuelas politécnicas el derecho a la autonomía, ejercida y comprendida de manera solidaria y responsable. Dicha autonomía garantiza el ejercicio de la libertad académica y el derecho a la búsqueda de la verdad, sin restricciones; el gobierno y gestión de sí mismas, en consonancia con los principios de alternancia, transparencia y los derechos políticos; y la producción de ciencia, tecnología, cultura y arte (CRE, 2008).

Por tanto, las personas jurídicas de derecho público sí pueden ser titulares de derechos constitucionales en la medida que la propia norma fundamental así lo establezca. Igualmente, ciertas construcciones dogmáticas han permitido ampliar los derechos de orden procesal o principios generales como la igualdad, también a la esfera de 
lo público. Esto significa que las personas jurídicas de derecho público también pueden proponer medidas cautelares constitucionales por sus propios derechos o en beneficio de los derechos de terceros, como veremos a continuación.

Sobre esta cuestión vale citar la jurisprudencia de la Corte Constitucional en su sentencia No. 2453-16-EP/19, que en lo principal indica:

16. La Corte Constitucional para el período de transición, en su sentencia No. 24-09-SEP-CC, determinó que en virtud de una aparente interpretación extensiva del artículo 86 numeral 1 de la CRE, las personas jurídicas de Derecho Público estaban facultadas para proponer garantías jurisdiccionales y reclamar, a través de estos mecanismos, sus derechos constitucionales, al igual que las personas naturales y jurídicas privadas. Es decir, estaban legitimados para ejercer el derecho de acción mediante la acción extraordinaria de protección, sin excepción alguna.

17. En las sentencias $0838-12-E P / 19,282-13-J P / 19$ y 2004-13-EP/19 esta Corte Constitucional se apartó de la línea jurisprudencial y, en efecto, consideró que las personas jurídicas públicas -en el caso concreto de la sentencia 0838-12-EP/19 el Banco Central del Ecuador-, no pueden comparecer a un proceso de acción extraordinaria de protección y alegar vulneraciones a derechos constitucionales sustantivos al menos en la medida en que no son titulares de estos derechos, sino que ejercen ciertas prerrogativas en función de competencias, atribuciones y obligaciones expresamente determinadas por la CRE y la ley. Ello, porque la CRE no reconoce derechos a las entidades públicas, sino que les reviste con ciertas facultades y atribuciones.

18. En la Sentencia 0838-12-EP/19, esta Corte concluyó que las entidades públicas podrán actuar como legitimados activos en procesos de acción extraordinaria de protección solo de manera excepcional, cuando se esgrima una vulneración a los derechos de protección en su dimensión procesal o, en el caso de ciertas instituciones públicas, cuando los derechos que aleguen estén relacionados con su actividad definitoria y, por tanto, reconocidos en la CRE, como esta Corte ratificó este pronunciamiento mediante la sentencia 282-13-JP/19. (CCE, Sentencia No. 2453-16-EP/19, párrs.16-18) 
Por lo dicho, hay que reconocer que también las entidades de derecho público pueden hacer uso de las garantías jurisdiccionales, como la Acción Extraordinaria de Protección, aunque excepcionalmente, cuando los derechos que se reputen violados sean explícitamente reconocidos a estos entes en la propia Constitución o bien se trate de derechos procesales. La razón de ser de esta última excepción, que ha sido avalada por la jurisprudencia de la Corte Constitucional del Ecuador, es bastante sencilla: las normas del debido proceso constitucional son normas de orden público que deben respetarse en todos los casos.

En el caso de las medidas cautelares constitucionales puede afirmarse algo similar. De acuerdo con la jurisprudencia de la Corte Constitucional del Ecuador:

es irrelevante si se trata de una persona natural por sus propios intereses o un servidor público en ejercicio de sus funciones y representación institucional. Lo importante es que se cumpla la finalidad de las medidas cautelares: prevenir o detener una violación de derechos (CCE. Sentencia No. 66-15-JC/19, 10 de septiembre de 2019, párrs. 38-39).

El caso del que se extrae la cita tiene que ver con el almacenamiento de hidrocarburos incautados por parte de la Policía Nacional que estaban siendo almacenados en las unidades de policía, que no cuentan con las instalaciones ni el personal para manejar estas sustancias. Ello producía el peligro de explosiones e incendios que podían afectar tanto la vida de muchas personas como su salud y el medio ambiente. Por ese motivo, una juez dispuso, como medida cautelar, el traslado de esas sustancias a EP-Petrocomercial y EP-Petroamazonas que contaban con las instalaciones y personal adecuado para almacenar estas sustancias.

El caso que nos ocupa resulta bastante sencillo para justificar que las entidades de derecho público puedan solicitar medidas cautelares. Sin embargo, la Corte Constitucional del Ecuador fijó acertadamente unas precisiones y limitaciones a esta posibilidad:

(...) con el fin de evitar posibles desnaturalizaciones en el uso de la medida cautelar por parte de servidores públicos, supuesto de carácter excepcional, conviene precisar que el Estado o sus servidores no pueden presentar me- 
didas cautelares para: la simple ejecución de sus competencias constitucionales o legales; para deslindarse de las obligaciones legales que les correspondan en virtud de sus competencias; o, peor aún para legitimar medidas o actos arbitrarios que puedan violar, restringir o limitar el debido proceso o derechos. Por ejemplo, no cabría interponer medidas cautelares para incautar productos hidrocarburíferos o para mejorar las instalaciones de las unidades policiales. El Estado y sus servidores públicos, en el desempeño de sus funciones, ejercen potestades o competencias y su deber primordial es "garantizar sin discriminación alguna el efectivo goce de los derechos (...) (CCE. Sentencia No. 66-15-JC/19, 10 de septiembre de 2019, párr. 41).

Adicionalmente, la Corte Constitucional precisó que los jueces, cuando tramiten medidas cautelares $u$ otras garantías jurisdiccionales presentadas por servidores públicos deben ser especialmente cuidadosos al analizar la petición para evitar que so pretexto de defensa de derechos de terceros se pretenda limitar, restringir o anular derechos de las personas. La Corte también señaló que no se puede utilizar conceptos como "interés general, bien común, seguridad pública, ciudadana o jurídica” para justificar los requisitos de gravedad y/o inminencia que exigen las medidas cautelares. Es decir, que estos requisitos no pueden ser satisfechos mediante alegaciones en abstracto sino mediante la alegación de circunstancias concretas (CCE. Sentencia No. 66-15-JC/19, 10 de septiembre de 2019, párr. 42).

En caso de que un juez verifique que la petición de medidas cautelares por parte de una entidad pública pretende desnaturalizar la garantía para: 1. Ejercer sus competencias atribuidas legalmente; 2. Deslindarse del ejercicio de sus competencias atribuidas legalmente; o, 3. Violentar el debido proceso o los derechos de las personas, debe rechazarla de plano, esto es, en la primera providencia. De igual forma deberá actuar el juez si la fundamentación de la medida cautelar es abstracta.

\subsection{La legitimación pasiva}

Conocemos la doctrina según la cual la Constitución vincula tanto a los poderes públicos como a los sujetos privados, aunque alguna precisión debe hacerse. En el caso de los sujetos privados, las 
medidas cautelares constitucionales resultan, en mi opinión procedentes, solamente cuando se demuestre alguno de los requisitos previstos en la ley para proponer una acción ordinaria de protección contra una persona física o jurídica privada: a) preste servicios públicos o impropios; b) presten servicios públicos por delegación o concesión; c) provoque daño grave; d) la persona afectada se encuentre en estado de subordinación o indefensión frente a un poder económico, social, cultural, religioso o de cualquier otro tipo; o, f) se trate de un acto discriminatorio (LOGJCC, art.41).

Esto tiene pleno sentido, a pesar de que la ley no lo señale así expresamente, porque un privado no puede proponer una acción de protección en tutela de sus derechos constitucionales en contra de otro privado fuera de los supuestos arriba enunciados. Por ende, si no se puede solicitar tutela principal del derecho debido al legitimado pasivo, tampoco se puede solicitar su protección cautelar.

Este es un criterio metodológico válido teniendo en cuenta que, por regla general, los distintos ordenamientos jurídicos (penal, administrativo, tributario, civil, etc.,) también prevén medidas cautelares y no es función de la jurisdicción constitucional reemplazar a las instancias judiciales ordinarias, pues ello implicaría desvirtuar la estructura jurisdiccional del Estado y desconocer la garantía institucional que representa la Función Judicial (CCE, Sentencia 1679-12$\mathrm{EP} / 20$ de 15 de enero de 2020).

En cuanto a los poderes públicos, todos son pasibles de medidas cautelares. Sin embargo, no proceden en contra de providencias judiciales ni en conjunto con la acción extraordinaria de protección (LOGJCC, art. 27).

\subsection{Amicus Curiae y Terceros con interés. Diferencias.}

En el trámite de medidas cautelares constitucionales es posible que se impliquen a terceros además del legitimado pasivo que tengan un interés en la causa. El artículo 12 de la LOGJCC distingue entre Amicus curiae y la figura del tercero con interés. De acuerdo con 
la doctrina en voz de Bazán (2014) y la jurisprudencia de la Corte Constitucional del Ecuador el amicus curiae comparece para presentar argumentos adicionales que ayuden a los jueces a resolver la causa. Sin embargo, no siendo partes procesales no pueden presentar pretensiones, ni practicar pruebas ni tampoco interponer recursos (CCE. Sentencia No. 29-20-IS/20, 2020, párr. 71). Además, el Amicus participa, formalmente, por medio de un escrito que es admisible hasta antes de la sentencia ${ }^{9}$, pero su participación en las audiencias públicas no es mandatorio, queda al criterio del juzgador.

Por el contrario, el tercero con interés no tiene un interés general en la causa sino un interés muy específico fijado por la ley. De acuerdo con el artículo 12 de la LOGJCC este tercero puede intervenir en el proceso, en cualquier estado de la causa (primera instancia, segunda instancia, ejecución) y no solamente "antes de la sentencia” como el Amicus curiae. Además, el tercero tiene un "interés directo" en que se mantenga (no en que se revoque) el acto u omisión que motiva la acción constitucional, en este caso, de medidas cautelares. Es decir, el tercero tiene un interés directo para apoyar a la parte accionada, por ejemplo, la Administración Pública en el mantenimiento de un acto administrativo.

Ahora bien, el tercerista, como es bien sabido, adquiere exactamente los mismos derechos y deberes procesales que las partes pudiendo presentar argumentos, pruebas y deducir pretensiones. De cualquier modo, la regulación de la tercería procesal en la LOGJCC es extremo deficiente y, quizá, también inconstitucional. Hubiera sido preferible adoptar un criterio similar al COGEP que exige ser un "tercero a quien las providencias judiciales causen perjuicio directo" y que, además, distingue entre tercerías coadyuvantes y excluyentes. En todo caso, téngase en cuenta que la disposición final de la LOGJCC remite al procedimiento civil de forma supletoria y en lo que fuera

9 Una interpretación amplia de esta disposición permitiría, sin inconveniente, presentar un escrito de Amicus curiae en segunda instancia (apelación) en el trámite de las garantías jurisdiccionales como acción de protección, habeas corpus, habeas data o acceso a la información pública. 
compatible con la naturaleza del derecho procesal constitucional. Este aspecto, sin embargo, no ha sido analizado a profundidad por la doctrina ecuatoriana.

No se avizoran motivos para restringir, en el caso de la LOGJCC, a que el tercero con interés solamente pueda concurrir en apoyo del accionado y no del accionante. Siguiendo el tenor literal de la ley, en el caso de las medidas cautelares constitucionales, un tercero solo adquiere derechos procesales si acredita interés directo en mantener el acto u omisión que amenaza o lesiona derechos constitucionales.

\section{Características Generales de las medidas cautelares}

\section{A. Temporalidad:}

Por regla general, las medidas cautelares buscan garantizar la eficacia del proceso judicial y en ese sentido están condicionadas a la duración de este. No tienen sentido una vez que ya se ha dictado sentencia. Por eso mismo, se dice que son temporales y explica que el artículo 33 de la LOGJCC obligue al juez a especificar las circunstancias de tiempo, modo y lugar de las medidas que decreta, en efecto, para mantener su carácter provisorio y no definitivo ${ }^{10}$.

Ahora bien, en nuestro sistema se permite también la posibilidad de presentar medidas cautelares autónomas cuando el derecho fundamental esté en peligro y la violación no haya concurrido aún. En ese caso, el objetivo de la institución se cumple por la adopción de

10 "Esta medida no es provisional, ni temporal, ni instrumental que son características propias de las medidas cautelares pues no fue una medida para asegurar luego el resultado de un proceso ni tampoco tiene una duración determinada ni responde a las circunstancias, pues tal como fue concedida por la Sala es una medida definitiva producto de una declaración de que se ha vulnerado derechos constitucionales, lo que es incompatible con la naturaleza de las medidas cautelares". (CCE. Sentencia No. 61-12-IS/19 de 23 de octubre de 2019, párr. 36). 
medidas que eviten la consumación del riesgo y, en ese sentido, dejan de ser temporales y se vuelven definitivas ${ }^{11}$. Se trataría de lo que la doctrina en voz de Peyrano (1997, pp.11-26) ha denominado medidas cautelares autosatisfactivas.

\section{B. No declarativa ni constitutiva de derechos:}

De acuerdo con la jurisprudencia de la Corte Constitucional del Ecuador "las medidas cautelares tienen una finalidad instrumental, consistente en asegurar el resultado de un proceso, o sea, evitar que luego de obtenida la sentencia favorable se frustre este resultado como consecuencia de la demora en obtener dicha resolución" (CCE. Sentencia No. 61-12-IS/19, de 23 de octubre de 2019).

En ese sentido, no pretenden declarar la violación de un derecho fundamental, que es cuestión reservada a la sentencia. Siguiendo la misma lógica, no se pretende que por medio de un auto de medidas cautelares se expidan auténticas sentencias declarativas de derechos personales, reales o de crédito. Tampoco sentencias constitutivas, que son aquellas que no declaran derechos, sino que constituyen, modifican o extinguen relaciones jurídicas. Ejemplos típicos son las sentencias de divorcio, de prescripción adquisitiva de dominio o las de adopción, en el ámbito civil y de familia, respectivamente. En casos en los que se ha verificado esta situación, la jurisprudencia sostiene que se ha desnaturalizado el objeto de la protección cautelar.

\section{No ordena la reparación integral:}

Como hemos visto, las medidas cautelares no pretenden declarar un derecho, ni su lesión, ni tampoco constituir relaciones jurídicas. Simplemente, existen para prevenir o cesar una lesión de derechos fundamentales. Por ese motivo, un auto de medidas cautelares no puede

11 Ejemplo paradigmático de una medida cautelar autosatisfactiva es (CCE. Sentencia No. 66-15-JC/19, 10 de septiembre de 2019). 
ordenar la reparación integral (CCE. Sentencia No. 66-15-JC/19, 10 de septiembre de 2019, párr. 20), entre otras cosas, porque sería necesario determinar el daño, fijar la relación de causalidad, descartar causas de exclusión de antijuridicidad (fuerza mayor, caso fortuito, el ejercicio de un derecho, etc.) y cuantificarlo. Y aquello es propio de un proceso de conocimiento, no de un proceso cautelar que, como veremos, se resuelve inaudita parte y sin necesidad de principio de prueba.

\section{No dispone la suspensión de leyes o actos normativos:}

El control de constitucionalidad en Ecuador es concentrado en la Corte Constitucional. Esto significa que solo este tribunal puede expulsar una norma del ordenamiento jurídico por considerarla contraria a la Constitución (CRE, 2008, art. 436). Los jueces, a lo mucho, pueden plantear una consulta de constitucionalidad si en el trámite de un caso concreto deben aplicar una norma jurídica con rango o fuerza de ley ${ }^{12}$ que estimen inconstitucional (Art. 428 CRE). En ese sentido, los jueces tampoco pueden ordenar como medida cautelar la suspensión provisional de una norma jurídica con rango o fuerza de ley (CCE. Sentencia 110-14-SEP-CC, 2014). Esto último también es una facultad privativa de la Corte Constitucional en el trámite de la acción pública y abstracta de inconstitucionalidad (LOGJCC, art. 79.6).

\section{E. Deben respetar el principio de proporcionalidad:}

El artículo 26 de la LOGJCC prevé un listado no taxativo, sino más bien ejemplificativo de las medidas cautelares que el juez constitucional puede ordenar, estas son: 1. La comunicación inmediata con la autoridad o persona que podría prevenir o detener la violación del derecho; 2. Suspender provisionalmente el acto lesivo de derechos; 3. Ordenar la vigilancia policial (que de ningún modo debe entenderse como medidas privativas de la libertad); 4 . La visita al lugar de

12 Véase el caso de los decretos-leyes en los artículos 140 y 148 de la Constitución ecuatoriana de 2008. 
los hechos. Sin embargo, como se dijo antes, la ley utiliza la formula "tales como" al momento de enunciar las medidas cautelares y señala también que estas "deberán ser adecuadas a la violación que se pretende evitar o detener".

El principio de proporcionalidad, sin entrar aquí a analizar las múltiples discusiones y críticas que se le ha formulado al método para su aplicación, la ponderación, tiene expreso reconocimiento en nuestro ordenamiento legal (Art.3 LOGJCC). En pocas palabras y consciente de la ultra simplificación significa que el juez, al conceder una medida cautelar, debe verificar que aquella sea a priori necesaria para proteger el derecho que se alega en peligro o en lesión actual, que sea idónea o útil para lograr el fin que persigue y finalmente que no afecte más de lo necesario derechos o intereses legítimos de terceros (Moreso, 2009).

\section{Requisitos materiales de procedencia}

Los requisitos para que una medida cautelar constitucional sea ordenada, conforme a la jurisprudencia de la Corte Constitucional son: 1) hechos creíbles o verosimilitud; 2) inminencia; 3) gravedad; y, 4) derechos amenazados o que se están violando. Veamos el alcance de cada uno de estos requisitos a continuación.

\subsection{Verosimilitud de la petición}

A criterio de la Corte Constitucional, la verosimilitud de:

los hechos creíbles deben desprenderse de la petición de medidas cautelares. Por la naturaleza de las medidas cautelares, al no ser una acción de conocimiento, no se requieren pruebas para demostrar la veracidad de lo descrito al momento de presentar la petición o demanda" (CCE. Sentencia No. 66-15-JC/19, 10 de septiembre de 2019, párr. 27).

Por ese motivo lo resuelto por el juez no equivale a un prejuzgamiento sobre los hechos o la posible responsabilidad por estos (Art. 28 de la 
LOGJCC). Igualmente, eso explica que la medida pueda ser revocada si es que los hechos no fueron ciertos o si no se presentaban los otros requisitos legales. Es decir, lo que el juez debe verificar es que la narrativa de los hechos sea coherente y que prima facie denote el peligro o violación de un derecho. Como bien decía Calamandrei (2006):

La cognición cautelar se limita, en todos los casos, a un juicio de probabilidades y de verosimilitud. Declarar la existencia del derecho es función de la providencia principal; en sede cautelar, basta que la existencia del derecho aparezca verosímil, esto es, basta que, según un cálculo de probabilidades, se pueda prever que la providencia principal declarará el derecho en sentido favorable a aquel que solicita la medida cautelar, por lo que el resultado de la cognición sumaria tiene el valor de una hipótesis.

\subsection{Inminencia o actualidad}

La Corte Constitucional ha dicho respecto de este requisito que "la inminencia tiene que ver con el tiempo. La relación entre un hecho u omisión con la violación del derecho tiene que ser estrecha. La violación del derecho tiene que estar pronto a suceder o estar sucediendo" (CCE. Sentencia No. 66-15-JC/19, 10 de septiembre de 2019, párr. 28). Sin embargo, nuestra jurisprudencia ha sido parca al desarrollar esta exigencia. De hecho, si uno lo analiza la inminencia es una cuestión de grado: un daño puede ser previsible y más o menos inminente (que está a punto de suceder o que está muy próximo en el tiempo) dependiendo de la certeza de su ocurrencia. Si el daño es actual, como se vio arriba, las medidas cautelares tienen que solicitarse en conjunto con una garantía de conocimiento.

\subsection{Gravedad del daño}

El requisito de la gravedad del daño viene establecido en la ley, que nos ofrece tres categorías que no necesariamente tienen que ser concurrentes: daño irreversible, daño intenso y daño frecuente o sistemático. Sobre esta cuestión, la Corte Constitucional de Ecuador ha indicado que: 
Un daño es irreversible cuando no se puede volver a un estado o condición anterior. Un daño es intenso cuando el daño es profundo, importante, como cuando produce dolor o su cuantificación es considerable o difícil de cuantificar. Una violación es frecuente cuando sucede habitualmente e incluso cuando se puede determinar un patrón en la violación (CCE. Sentencia No. 66-15-JC/19, 10 de septiembre de 2019, párr. 28).

\subsection{Derechos fundamentales amenazados o violados}

El artículo 87 de la CRE habilita al accionante a solicitar medidas cautelares cuando un "derecho" se encuentre amenazado o bien para cesar una lesión en curso. En todo caso esa disposición se complementa con los artículos 424 y 426 de la norma fundamental que realiza una apertura a los tratados internacionales de derechos humanos, por lo cual en casos en los que un tratado en esta materia especifica reconozca "derechos más favorables a los contenidos en la Constitución, prevalecerán sobre cualquier otra norma jurídica o acto del poder público". Es decir, en el caso de que la Constitución ecuatoriana no prevea un derecho en particular, pero ese derecho sí esté reconocido en un tratado internacional de derechos humanos ratificado por el Ecuador, ese derecho será directamente aplicable por los jueces de la república sin necesidad de desarrollo legislativo. En sentido similar, el artículo 11.5 de la Carta Suprema reconoce que la "interpretación" aplicable, tanto a los derechos como a las garantías jurisdiccionales, será la que más favorezca a su efectiva vigencia ${ }^{13}$.

Esto significa que los jueces nacionales deben aplicar directamente la interpretación más favorable de los derechos proveniente de la jurisprudencia de los órganos autorizados para interpretar los tratados internacionales de derechos humanos, por ejemplo, la jurisprudencia de la Corte Interamericana de Derechos Humanos, de la cual

13 "La amenaza o violación tiene que ser a derechos reconocidos en la Constitución o en instrumentos internacionales de derechos humanos". No podemos ingresar aquí a explicar la distinción entre "instrumentos" y "tratados" en materia de derechos humanos. (CCE. Sentencia No. 66-15-JC/19, de 10 de septiembre de 2019, p. 7.) 
Ecuador es un sujeto de su jurisdicción, aunque la interpretación que configura los contenidos y alcances de esos derechos sean más restrictivos a nivel nacional. Todo esto en el sentido de que el propio artículo 11 de la CRE reconoce que los derechos consagrados en su texto no son excluyentes y exclusivos, sino que exigen un desarrollo progresivo a través de la jurisprudencia (SAGÜÉS, 2010).

Por tanto, las medidas cautelares pueden ser propuestas en casos de peligro o lesión de un derecho constitucional o un derecho humano, es decir, en casos de lo que genéricamente se conoce como los derechos fundamentales de la persona ${ }^{14}$.

\section{Especificidades del procedimiento constitucional}

En que corresponde al procedimiento de las medidas cautelares constitucionales, conviene poner de manifiesto algunas características especiales de éste.

1. Jurisdicción y competencia: Como en el resto de las garantías jurisdiccionales que no son de competencia exclusiva de la Corte Constitucional, las medidas cautelares pueden solicitarse ante el juez de primera instancia competente que será uno determinado por el sorteo de ley en razón del lugar "en donde se origina el acto u omisión o donde se producen sus efectos” (Art. 7 LOGJCC).

2. No se requiere patrocinio de abogado para presentar la petición de medidas cautelares (Art. 8.7 LOGJCC).

14 La idea de los derechos fundamentales para Ferrajoli (2006) es que se traten de derechos universales, de los que toda persona sea titular: "Son derechos fundamentales, en el ordenamiento italiano o alemán, los derechos universales e indisponibles establecidos por el derecho positivo italiano o alemán. Son derechos fundamentales, en el ordenamiento internacional, los derechos universales e indisponibles establecidos en la Declaración Universal de los Derechos Humanos de 1948, en los pactos internacionales de 1966 y en las demás convenciones internacionales sobre los derechos humanos". Cfr. (Párrs 116-117). 
3. Las medidas cautelares constitucionales pueden solicitarse oralmente, solo con un documento de identificación válido (Art. 7 LOGJCC).

4. Son hábiles todos los días y horas (Art. 8.3 LOGJCC).

5. Inaudita parte: las medidas cautelares constitucionales se pueden conceder, rechazar, modificar o revocar sin necesidad de escuchar en audiencia a las partes procesales. De hecho, la audiencia es excepcional (Art. 36 LOGJCC).

6. Para comunicar sus decisiones, el juez puede utilizar los medios más eficaces a su alcance como una llamada telefónica o un fax, por ejemplo (Art. 33 LOGJCC).

7. Medidas cautelares autónomas o en conjunto: si lo que se pretende atajar con las medidas cautelares es un peligro inminente a un derecho fundamental procede la medida cautelar autónoma, pero si la lesión al derecho fundamental ya ocurrió corresponde una medida cautelar en conjunto con una garantía jurisdiccional de conocimiento (por ejemplo, acción de protección). El juez debe obrar diligentemente y observar estas cuestiones para no desnaturalizar el objeto de las medidas cautelares autónomas. En ese sentido, en virtud del principio iura novit curiae está obligado a enmendar el error del peticionario y tramitar una garantía jurisdiccional de conocimiento junto a la cautelar ${ }^{15}$.

15 "Esta Corte advierte que, en la actualidad, de ocurrir casos similares, en los que se alegue vulneración de derechos en una medida cautelar autónoma, los jueces constitucionales tienen el deber de enmendar el error en que incurre el solicitante y tramitar la medida cautelar en conjunto con la garantía de conocimiento que corresponda, en cumplimiento de la jurisprudencia vigente". Cfr. (CCE. Sentencia No. 61-12-IS/19). También, (CCE. Sentencia No. 364-16-SEP-CC del 15 de noviembre de 2016). 


\subsection{El régimen de impugnación horizontal y vertical de las medidas cautelares constitucionales}

La ley no aclara que naturaleza tienen los autos de medidas cautelares. Claramente, no son autos de sustanciación, pero tampoco son sentencias. Desde nuestro punto de vista, partiendo de la clasificación del Código Orgánico General de Procesos (COGEP), son autos interlocutorios, es decir, una providencia que resuelve cuestiones procesales que no siendo materia de sentencia pueden afectar los derechos de las partes. Pero vale advertirlo desde ahora, si bien la disposición final de la LOGJCC invita a colmar las lagunas con las disposiciones del procedimiento civil, aquello solo es pertinente cuando fuera conforme a la naturaleza del derecho procesal constitucional. Por ese motivo, dichas remisiones deberán ser debidamente argumentadas y, por el contrario, ha de partirse de la premisa de que el derecho procesal constitucional es un sistema autorregulado.

Sobre las posibilidades de impugnación de un auto de medidas cautelares hemos de mencionar que, de acuerdo con el artículo 33 de la LOGJCC, en caso de que estas se concedan o se denieguen, no cabe recurso de apelación lo cual ha sido declarado como conforme con la Constitución (CCE. Sentencia No. 002-17-SIN-CC, del 8 de febrero de 2017) ${ }^{16}$.

De otro lado, conforme el artículo 35 de la LOGJCC solo se puede solicitar revocatoria una vez que las medidas cautelares hayan sido acatadas, es decir, la ley presupone que el juez ha decidido conceder las medidas solicitadas. En ese sentido, no es procedente solicitar la revocatoria de la negativa del juez de conceder medidas cautelares. Y si de hecho se presenta, el juez debe desechar el recurso horizontal in límine. Los únicos recursos horizontales que pueden aceptarse en caso de que la petición de medidas cautelares sea rechazada son la

16 En esta sentencia se ratifica la constitucionalidad del articulo 33 LOGJCC y declara que no es contraria a la garantía de recurrir de los fallos contenida en el art. 76 (7) (m) de la Constitución; asimismo ratifica la constitucionalidad del art. 35 LOGJCC. 
aclaración y la ampliación y, por supuesto, sin que estos puedan mal utilizarse para cambiar el sentido de la decisión. Como veremos más adelante, frente a este auto interlocutorio tampoco cabe acción extraordinaria de protección.

Partamos ahora del supuesto contrario: se conceden las medidas cautelares. ¿Qué recursos puede interponer la parte afectada por la providencia? Como hemos visto, no hay norma que impida proponer recursos como la aclaración y la ampliación, que por regla general se conceden con efectos suspensivos según el procedimiento civil. Sin embargo, los principios legales que orientan las medidas cautelares constitucionales son la celeridad, la eficacia y la inmediatez (Arts. 29 y 33 LOGJCC). Si estos recursos se concedieren con efecto suspensivo las medidas cautelares constitucionales no podrían cumplir su objeto que es prevenir o cesar eficazmente una violación de derechos fundamentales. En ese sentido, teniendo en cuenta que ni la aclaración ni la ampliación pretenden alterar el sentido de la decisión, opinamos que las medidas cautelares dispuestas judicialmente deben cumplirse de inmediato.

En cuanto a la revocatoria, es posible solicitarla en cualquier momento, es decir, no es un recurso que tenga caducidad procesal. En ese sentido, la Corte Constitucional del Ecuador ha señalado:

(...) que estas son revocables por causas sobrevinientes que merecen ser justificadas por quien solicita la revocatoria de ellas y razonadas por el juzgador que las adopta (CCE. Sentencia No. 052-11-SEP-CC, 2012, p.19).

Lo que se debe justificar, según el artículo 35 de la LOGJCC es alguna de las siguientes circunstancias:

1. Que se evitó la violación de derechos.

2. Que cesó la violación de derechos.

3. Que cesaron los requisitos previstos en la ley. 
4. Que la petición de medidas cautelares no tenía fundamento. Sobra decir que esta es la causal alegada por excelencia para requerir la revocatoria de las providencias cautelares.

Solamente en el caso de que el juez niegue la revocatoria de las medidas cautelares, se podrá apelar en la misma audiencia o en el término de tres días desde que el juez dictó su auto por escrito (CCE. Sentencia No. 001-11-SCN-CC, de 9 de Febrero del 2011). La apelación es tramitada por una sala de la Corte Provincial de Justicia del lugar del juez que conoce la petición de medidas cautelares. Este tribunal, por otro lado, se determina por sorteo y no necesariamente es el superior regular del juez ${ }^{17}$. Por ejemplo, si las medidas cautelares son resueltas por un juez penal, es perfectamente posible que el tribunal de apelación sea uno especializado en materia civil.

De la decisión del tribunal de apelación no cabe recurso de casación tratándose de jurisdicción constitucional sobre la cual la Corte Nacional de Justicia no tiene competencia. Conforme los criterios actuales de la Corte Constitucional, tampoco cabe de esta decisión acción extraordinaria de protección porque el juez de instancia puede, si surgen nuevos hechos o argumentos justificados, revocar la medida cautelar. En ese sentido, no es una decisión definitiva.

\subsection{Un requisito fundamental para la procedencia de la revocatoria}

"Para que proceda la revocatoria (de las medidas cautelares constitucionales), la institución o persona a quien se haya delegado o las partes, deberán informar a la jueza o juez sobre la ejecución de las medidas" (Art.35 LOGJCC). En efecto, la disposición citada inicia mencionando que "la revocatoria de las medidas cautelares procederá sólo cuando se haya evitado o interrumpido la violación de derechos". El tenor literal de la ley nos lleva a afirmar que el

17 Art. 24 LOGJCC: "La apelación será conocida por la Corte Provincial; si hubiere más de una sala, se radicará por sorteo." 
informe de cumplimiento por parte del legitimado pasivo es de carácter obligatorio y que sin aquel la revocatoria puede ser negada de forma liminar. Dicho de otro modo: la ley parece apuntar a que es requisito acatar las medidas cautelares y solo después poder solicitar su revocatoria.

Esta disposición tiene su razón de ser, en primer lugar, en la importancia de los bienes jurídicos que se encuentran en peligro o lesión que son aquellos "fundamentales". En segundo lugar, que, en caso contrario, las medidas cautelares dispuestas judicialmente no tuvieran eficacia alguna. Sin perjuicio de lo dicho, la formación de la Corte Constitucional cesada mantiene una jurisprudencia que parecería admitir una excepción a la regla formulada cuando lo que se alega es la falta de fundamento de las medidas cautelares. Hasta el momento, dicho precedente no ha sido revocado ${ }^{18}$.

\subsection{Improcedencia de las medidas cautelares constitucionales}

Hay que distinguir entre causales de improcedencia y prohibiciones en el tema de las medidas cautelares constitucionales. Hay coincidencias: si el juez verifica una causal de improcedencia o una prohibición debe negar o, en su caso, revocar la medida cautelar. La diferencia radica en que mientras que las prohibiciones son fácilmente apreciables de oficio por el juez, las prohibiciones generalmente requerirán que el legitimado activo haya podido defenderse y poner en conocimiento del juez la circunstancia.

18 “(...) cuando la solicitud de revocatoria de las medidas cautelares sea interpuesta por considerar que no existe fundamento constitucional para su adopción, la condición de presentar un informe sobre el cumplimiento de las medidas cautelares concedidas para que proceda dicha solicitud de revocatoria...no constituye impedimento o motivo para que el juez constitucional, que incluye a las Cortes Provinciales de Justicia, en sede de apelación, valore y se pronuncie sobre los argumentos o pruebas presentadas con tal solicitud de revocatoria, pudiendo incluso convocar a audiencia para discutirlo (...)". (CCE. Sentencia No. 052-11-SEP-CC, 15 de diciembre de 2011, p. 19). 
Es improcedente la medida cautelar cuando lo que se pretende es "ordenar medidas privativas de la libertad" (Art.26 LOGJCC). Al respecto, hay que señalar que las medidas privativas de la libertad "ambulatoria" solo pueden ser dispuestas por el juez penal competente, como es el caso de la prisión preventiva, la prohibición de salida del país, la obligación de presentarse periódicamente ante el juez, el arresto domiciliario, utilización de dispositivos de vigilancia electrónica o la detención (Art. 522 COIP).

La ley también indica que "no procederán cuando existan medidas cautelares en las vías administrativas u ordinarias" (Art. 27 LOGJCC). Sin embargo, una interpretación literal de esta norma sería inconstitucional. En efecto, cuando el ordenamiento jurídico nos brinde la posibilidad de pedir medidas cautelares ante la jurisdicción ordinaria y aquellas sean adecuadas y eficaces, debemos recurrir a estas.

Sin embargo, si el legislador no ha previsto un régimen cautelar aplicable al caso concreto o bien ese régimen es inadecuado para la protección del derecho fundamental o ineficaz para la tutela a tiempo del derecho, consideramos que la jurisdicción constitucional queda habilitada. Por supuesto, la argumentación sobre la falta de idoneidad y eficacia de la jurisdicción ordinaria corresponderá al peticionario.

Adicionalmente, la mera existencia de medidas cautelares en el procedimiento administrativo no pueden ser un argumento válido para negar medidas cautelares. Los intereses de la administración y el administrado son muchas veces contrapuestos y aquellos no operan bajo los mismos estándares de independencia e imparcialidad con el que deberían operar los jueces (Art. 76 CRE).

También es improcedente ordenar una medida cautelar constitucional "cuando se trate de ejecución de órdenes judiciales" (Art. 27 LOGJCC). Esto significa que no se puede utilizar la protección cautelar para suspender ningún tipo de providencia judicial, mucho menos la ejecución de una sentencia ejecutoriada.

En el mismo sentido, tampoco procede la medida cautelar constitucional cuando se interpone en conjunto con la acción extraor- 
dinaria de protección (Art. 27 LOGJCC). Básicamente, porque de lo contrario la jurisdicción de la Corte Constitucional se convertiría en una suerte de "cuarta instancia" que desfiguraría la regular actuación de los órganos de justicia y la seguridad jurídica. Por ese mismo motivo, ni la interposición de la acción extraordinaria de protección ni su admisión a trámite suspenden la ejecución de la decisión judicial impugnada (Art. 62 LOGJCC).

Como se ha podido ver, las causas de improcedencia son fácilmente verificables a partir de la propia pretensión del accionante de la medida cautelar. En cambio, las prohibiciones generalmente deberán ser alegadas y probadas. Así, está expresamente prohibido proponer una medida cautelar para "contrarrestar" otra medida cautelar (Art. 37 LOGJCC). Igualmente, también está prohibido proponer varias acciones de medida cautelar de forma sucesiva o simultánea con identidad subjetiva y objetiva (Art. 23 LOGJCC). Finalmente, existen ocasiones en las que los peticionarios o los abogados de aquellos pueden actuar en franco "abuso de derecho" lo que ocurre cuando se presenten "peticiones de medidas cautelares de mala fe, desnaturalicen los objetivos de las acciones o medidas o con ánimo de causar daño" (Art. 23 LOGJCC).

Sobre esto último, la legislación actual faculta a los jueces a imponer multas a los abogados de hasta 3 salarios básicos unificados (SBU) que en caso de impago conducen a la suspensión temporal del ejercicio profesional (Art. 336 COFJ). Además, en caso de abuso del derecho que provoque un daño, se genera responsabilidad extracontractual por la cual es procedente iniciar un proceso de daños y perjuicios por cuerda separada. Además, la ley no descarta la posibilidad de responsabilidad penal.

\subsection{Improcedencia de la Acción Extraordinaria de Protección en contra de un auto de medidas cautelares}

De acuerdo con lo previsto en la Constitución y la LOGJCC, la Acción Extraordinaria de Protección (AEP) es una garantía jurisdiccional cuyo conocimiento corresponde a la Corte Constitucional del 
Ecuador para tutelar el respeto de los derechos constitucionales y del debido proceso en los procesos judiciales que terminen con un auto definitivo y resoluciones con fuerza de sentencia definitiva. Con ciertos matices en los que no cabe ahondar aquí, esta garantía también se extiende a los laudos de arbitraje.

La actual formación de la Corte Constitucional ha señalado que los autos de medidas cautelares no son autos definitivos conforme el artículo 94 de la CRE y, por tanto, no son susceptibles de ser impugnados por medio de una AEP. La argumentación de la Corte se centra en que: 1 . La concesión de medidas cautelares no constituye prejuzgamiento sobre la presunta violación de derechos; 2. Que la concesión o negativa de medidas cautelares carece de valor probatorio (CCE. Sentencia No. 1589-13-EP/19, del 28 de octubre de 2019, párrs. 3233); 3. Que las medidas cautelares, por su naturaleza, no son definitivas y pueden ser revocadas o modificadas en los casos previstos en la ley; 4 . En línea con el argumento anterior, que los autos de medidas cautelares no constituyen cosa juzgada material (CCE. Sentencia No. 61-12-IS/19, del 23 de octubre de 2019, párrs. 27-28).

Es importante destacar, en todo caso, que la formación anterior de la Corte Constitucional del Ecuador consideraba que sí era procedente interponer una AEP en contra de autos de medidas cautelares (CCE. Sentencia No. 261-15-SEP-CC, 12 de agosto de 2015). De allí la importancia del concepto de autonomía procesal de la Corte Constitucional, en definitiva, el intérprete autorizado de las disposiciones jurídicas puede atribuir un significado u otro al texto, con consecuencias tan relevantes como la expuesta.

\subsection{Improcedencia de la Acción de Incumplimiento en contra de un auto de medidas cautelares}

La actual formación de la Corte Constitucional ha señalado en su jurisprudencia que la acción de incumplimiento de sentencias no es procedente respecto de autos de medidas cautelares constitucionales (CCE. Corte Constitucional del Ecuador. Sentencia No. 61-12-IS/19, del 23 de octubre de 2019). A diferencia de la acción por incumplimiento 
(Art. 93 CRE), la acción de incumplimiento no está expresamente prevista en la Constitución como una garantía jurisdiccional que aparecen en el título III capítulo III de la CRE. La acción de incumplimiento aparece como una "atribución" de la Corte Constitucional y tiene como finalidad "conocer y sancionar el incumplimiento de sentencias y dictámenes constitucionales" (Art. 436.9 CRE). No es este el espacio apropiado para el desarrollo y distinción de estas dos acciones. Baste con señalar que lo que se pretende con la acción de incumplimiento es la realización del último elemento de la tutela judicial efectiva, esto es, el cumplimiento efectivo de las decisiones de los jueces de garantías constitucionales y la propia Corte Constitucional ${ }^{19}$.

Ahora bien, otro cambio jurisprudencial que evidencia la autonomía procesal de la Corte Constitucional es el cambio de jurisprudencia: mientras que la formación cesada admitía la acción de incumplimiento respecto de autos de medidas cautelares ${ }^{20}$, a decir verdad, sin mayor justificación o análisis, la actual formación ha decidido que

19 En palabras de la Corte Constitucional: "la Constitución y la ley establece que a través de la acción de incumplimiento puede demandarse el cumplimiento de una sentencia o un dictamen constitucional en caso de que este no haya sido ejecutado o haya sido ejecutado defectuosamente. Ello trae como consecuencia que la competencia de la Corte Constitucional se circunscriba exclusivamente a pronunciarse sobre el cumplimiento o ejecución de lo decidido por las autoridades jurisdiccionales en materia constitucional y no a realizar un análisis del fondo del asunto que fue objeto del proceso". Cfr. (CCE. Sentencia No. 61-12-IS/19, del 23 de octubre de 2019, párr. 24).

20 Cfr. CCE: Sentencia No. 23-13-IS/19 del 20 de agosto de 2019 (Niega acción de incumplimiento pues las cautelares fueron cumplidas); 2) Sentencia No. 026-14-SISCC del 13 de noviembre de 2014 (Niega acción de incumplimiento pues las cautelares fueron cumplidas; 3) Sentencia No. 032-17-S1S-CC del 2 de agosto de 2017 (Niega acción de incumplimiento pues la cautelar cuyo incumplimiento se acusa es inejecutable); 4) Sentencia No. 040-17-SIS-CC del 23 de agosto de 2017 (Niega acción de incumplimiento pues la cautelar fue revocada); 5) Sentencia No. 004-18-SIS-CC del 7 de febrero de 2018 (Niega acción de incumplimiento pues el fundamento de la cautelar quedó insubsistente). 
aquella acción es improcedente respecto de los autos interlocutorios de medidas cautelares constitucionales ${ }^{21}$.

Los motivos son los siguientes: 1 . Los autos de medidas cautelares constitucionales no son "sentencias" ni tampoco "dictámenes" y, por tanto, no son objeto de la acción de incumplimiento; 2. Precisamente, los autos de medidas cautelares constitucionales se caracterizan por ser provisionales, revocables y por no constituir prejuzgamiento y de allí que la acción en comento tampoco se ajuste a la decisión judicial; 3 . No es deseable que la Corte Constitucional interfiera con las competencias de los jueces de garantías constitucionales que también pueden modificar o revocar esas medidas cautelares. 4. Además, son los propios jueces de garantías constitucionales los que deben asumir el deber de ejecutar sus propias decisiones y para ello, la LOGJCC les confiere herramientas según el artículo 22 de la referida ley. En ese sentido, pueden: 1 . En caso de que el incumplimiento provoque daños, tramitar en procedimiento sumario un incidente de daños y perjuicios en contra del responsable público o privado; 2 . Iniciar las acciones para la eventual destitución del funcionario judicial o servidor público que incumple el auto de medidas cautelares.

Una parte de la doctrina ecuatoriana afirma que el artículo 30 de la LOGJCC habilitaría expresamente la acción de incumplimiento en el caso de los autos de medidas cautelares constitucionales. La disposición citada reza: "El incumplimiento de las medidas cautelares será sancionado de la misma manera que en los casos de incumplimiento de la sentencia en las garantías jurisdiccionales constitucionales" (LOGJCC).

21 "Por lo expuesto, esta Corte Constitucional se aparta del criterio jurisprudencial anterior en el que se presupone que el cumplimiento de las resoluciones dictadas en procesos de medidas cautelares autónomas o las mismas medidas cautelares eran materia de una acción de incumplimiento", pues el Pleno de este Organismo sostiene que la ejecución de una medida cautelar o decisiones provenientes de procesos de medidas cautelares autónomas no pueden ser objeto de dicha garantía jurisdiccional ante la Corte Constitucional”. Cfr. (CCE. Sentencia No. 61-12-IS/19, del 23 de octubre de 2019, párr. 29). 
En efecto, una interpretación literal nos llevaría a equiparar automáticamente los autos de medidas cautelares con sentencias y, por tanto, habilitar de inmediato la acción de incumplimiento ante la Corte Constitucional. Sin embargo, también podría interpretarse aquella disposición de modo diverso. Ejemplo: el artículo 30 de la LOGJCC se refiere a que el incumplimiento de los autos de medidas cautelares se sancionará de la misma forma que se sanciona el incumplimiento de una sentencia. Pero, entonces, lo que se vuelve equiparable es el régimen sancionatorio, es decir, lo que él puede disponer para coactivamente asegurar el cumplimiento de su decisión, pero eso en nada altera la naturaleza de auto interlocutorio de las providencias cautelares. Esta interpretación tiene pleno sentido si se tiene en cuenta que el mencionado artículo 22 de la LOGJCC se refiere únicamente al incumplimiento de "la sentencia o acuerdo reparatorio" y que en ningún momento se refiere a la acción de incumplimiento.

Finalmente, cabe presentar un matiz: la actual formación de la Corte Constitucional ha señalado que excepcionalmente es procedente la acción de incumplimiento cuando la medida cautelar se encuentre inmersa en un caso de decisiones constitucionales contradictorias (CCE. Sentencia No. 61-12-IS/19, del 23 de octubre de 2019, párr. 29). Así, por ejemplo, sería procedente una acción de incumplimiento dirigida a resolver conflictos jurisdiccionales que impidan la ejecución de una sentencia. Así, la Corte Constitucional del Ecuador ha aceptado esta acción indicando que una medida cautelar autónoma era contradictoria respecto de una sentencia de acción de protección, por lo que dejó sin efecto la medida cautelar (CCE. Sentencia No. 045-15-SIS-CC, del 9 de julio de 2015.)

\subsection{Excepciones al principio de preclusión procesal}

El principio de preclusión es, sin lugar a duda, un pilar fundamental del derecho procesal. Para la Corte Constitucional del Ecuador:

La preclusión procesal es principio general del derecho, por el cual las etapas procesales se van cerrando sucesivamente, es decir, la posibilidad de contradicción de las partes en las fases procesales una vez evacuadas, 
se cierran inevitablemente y no es posible volver atrás, ya que hacerlo implicaría un desbalance procesal entre los contendientes. Es así que, conforme a este principio, se asegura, no solo el respeto a las etapas existentes en un proceso, ocasionando que el cierre sucesivo de estas no haga posible volver a revisarlas nuevamente, sino que además se garantiza la observancia de las normas jurídicas aplicables a cada una de las fases, lo cual genera certidumbre de que el ordenamiento jurídico será aplicado correctamente, en definitiva, da certeza de seguridad jurídica en la tramitación de un proceso (CCE. Sentencia No. 226-15-SEP-CC, 2015).

Como sabemos bien, una de las manifestaciones más claras del principio de preclusión aparece a nivel procesal en la distinción entre la fase de admisibilidad y la fase de decisión sobre el fondo de la controversia. Se trata, desde mi perspectiva, de una división funcional del trabajo para el correcto funcionamiento -en generaldel sistema de justicia. En ese sentido, mientras que en la fase de admisibilidad (que corresponde a la Sala de Admisión ${ }^{22}$ ) se verifican cuestiones formales como haber recurrido dentro del término legal, que el escrito contenga los requisitos formales mínimos para ser tramitados o, en el caso que nos ocupa, que la acción de incumplimiento esté dirigida contra una sentencia o dictamen, en la fase de análisis sobre el fondo (que le corresponde a la Corte Constitucional en pleno) no debe haber discusión alguna sobre estas cuestiones $^{23}$. Los jueces deben limitarse a decidir, tomando la decisión de admisibilidad como un presupuesto, sobre si se cumplió o no la decisión jurisdiccional en cuestión.

22 Vid. Arts. 188, 189 y 197 de la LOGJCC.

23 Se trata de una regla jurisprudencial erga omnes según el artículo 436 de la CRE: "Una vez que la Sala de Admisión ha admitido a trámite una acción extraordinaria de protección, y por tanto se ha superado la fase de admisión, el Pleno de la Corte Constitucional en la fase de procedibilidad deberá dictar sentencia en la cual se analice el fondo del asunto, esto es se verifique la vulneración de derechos en la decisión judicial impugnada, sin que pueda volver a analizar los presupuestos de admisibilidad ya superados en la primera fase de esta acción”. Cfr. (CCE. Sentencia No. 037-16-SEP-CC, 2016). 
Empero, ha sido la Corte Constitucional del Ecuador la que a golpe de jurisprudencia ha ido desarrollando "excepciones" al principio de preclusión arriba comentado. Esa jurisprudencia se concentra en la acción extraordinaria de protección ${ }^{24}$, pero las mismas razones son extensibles a la acción de incumplimiento. En síntesis, existe una excepción al principio de preclusión si se recurre un auto de medidas cautelares autónomas mediante una acción de incumplimiento de sentencias y dictámenes constitucionales. Dicho de otro modo: si la sala de admisión de la Corte Constitucional cesada admitió este tipo de acciones, el pleno de la actual formación de la Corte Constitucional no está obligado a dictar una decisión sobre si existió o no incumplimiento, debe limitarse a rechazar la acción porque aquella fue admitida de manera improcedente.

Lo mismo puede decirse respecto de una acción extraordinaria de protección respecto de un auto de medidas cautelares. Si una sala de admisión de la formación anterior de la Corte Constitucional del Ecuador, el pleno actual del máximo órgano de justicia constitucional en el Ecuador puede desechar la acción sin necesidad de pronunciarse sobre el fondo.

\section{VI. ¿Posibilidades para la contratutela?}

Sabemos bien que, en el derecho cautelar, la contra atacara de las medidas provisionales son las medidas de contracautela, es decir, una exigencia impuesta por el juez para el peticionario de las medidas

24 La Corte Constitucional estableció una excepción a la regla jurisprudencial establecida en la sentencia No. 037-16-SEP-CC, por considerar que las demandas de acciones constitucionales necesariamente deben cumplir con los requisitos básicos que guardan relación con el objeto de la acción referida. En tal sentido, si en la etapa de sustanciación el Pleno de la Corte identifica, de oficio, que el acto impugnado no es una sentencia, un auto definitivo o una resolución con fuerza de sentencia, no puede verse obligado a pronunciarse sobre el mérito del caso, pues hacerlo desnaturalizaría la acción extraordinaria de protección. Cfr. (CCE. Sentencia No. 154-12-EP/19, 2019). 
cautelares para, eventualmente, responder de los daños y perjuicios que puedan causar injustificadamente aquellas sobre el legitimado pasivo o terceros. Lamentablemente, el estudio de la contracautela se ha circunscrito siempre al ámbito patrimonial (así los ejemplos clásicos son la caución y la fianza personal).

En todo caso, no hay que olvidar que los derechos fundamentales de contenido económico también son tutelables por medio de la acción de protección y las medidas cautelares, aunque la distinción entre la legalidad/constitucionalidad rebasa la idea de este texto, es una afirmación correcta. Pero fuera de estos casos, difícilmente se puede pensar en ejemplos de contracautela. Más allá de aquello, en derecho público el juez solo puede hacer lo que está permitido y está institución no consta en la LOGJCC.

\section{Corrupción judicial y abuso del derecho procesal constitucional}

Es imprescindible poner de manifiesto, antes de concluir este artículo, que la nueva jurisprudencia procesal de la Corte Constitucional del Ecuador respecto de las medidas cautelares me parece correcta en la mayoría de sus aspectos. Me refiero, especialmente, a la improcedencia de la acción extraordinaria de protección y a la acción de incumplimiento de sentencias respecto de autos de medidas cautelares.

Pero no es novedad que las medidas cautelares autónomas son constantemente utilizadas, con la anuencia de un aparato judicial mayoritariamente corrupto, para declarar derechos o constituir relaciones jurídicas de forma definitiva, desnaturalizando totalmente la razón de ser de las medidas cautelares autónomas, ignorando que existen vías cautelares en la jurisdicción ordinaria ${ }^{25}$.

25 Este problema no es desconocido en absoluto para la Corte Constitucional del Ecuador, vid. (CCE. Sentencia No. 61-12-IS/19, del 23 de octubre de 2019, párr. 36). 
Además, también por la galopante corrupción que aflige a nuestra nación, los tribunales de apelación no representan mayor garantía de la correcta aplicación del derecho. Y si no bastase lo comentado, los jueces frecuentemente ignoran e incumplen con la obligación de remitir sus decisiones sobre medidas cautelares para una eventual selección de la Corte Constitucional (Arts. 25 y 38 LOGJCC), que dicho sea de paso es una de las pocas instituciones del país que goza del prestigio y respeto de la ciudadanía.

El problema es claro: la corrupción ha perfeccionado un modus operandi en el que un juez penal puede ordenar algo propio de un juicio civil, sin pruebas, de inmediato y sin escuchar a la contraparte. Y si la corrupción extiende sus tentáculos al tribunal de alzada poco o nada hay que hacer por el infortunado ciudadano preso en las fauces del sistema. ¿Qué hacer ante tan inquietante realidad? La respuesta a largo término es reconstruirnos como sociedad, por supuesto. Una respuesta mediata podría pasar por reformar la LOGJCC y el COFJ y crear una jurisdicción especializada en materia constitucional a nivel nacional, lo que sería una forma de concentrar los esfuerzos de capacitación judicial y atención disciplinaria.

\section{Referencias Bibliográficas}

Alexy, R. (1993). Teoría de los derechos fundamentales. Madrid: Centro de Estudios Constitucionales.

Bazán, V. (2014). Amicus Curiae, Justicia Constitucional y Fortalecimiento Cualitativo Del Debate Jurisdiccional. Revista Derecho del Estado 33.

Calamandrei, P. (2006). Introducción al estudio sistemático de las medidas cautelares. Lima: Ara Ediciones.

Cruz Villalón, P. (1992). Dos cuestiones de titularidad de derechos: los extranjeros; las personas jurídicas. Revista española de derecho constitucional 35. 
Díaz Lema, J. ¿Tienen derechos fundamentales las personas jurídico-públicas? Revista de administración pública 120.

Ferrajoli, L. (2006). Sobre los derechos fundamentales. Cuestiones constitucionales 15.

Ferrajoli, L. (2006). Las garantías constitucionales de los derechos fundamentales. DOXA, Cuadernos de Filosofía del Derecho, 29.

Ferrer Mac-Gregor, E. \& Fiz-Zamudio, H. (2013). Panorámica del derecho procesal constitucional y convencional. México: Marcial Pons, Ediciones Jurídicas y Sociales.

Moreso, J. (2009). Alexy y la aritmética de la ponderación. Derechos sociales y ponderación. Madrid: Fundación Coloquio Jurídico Europeo.

Peyrano, J. (1997). Reformulación de la teoría de las medidas cautelares: Tutela de urgencia. Medidas autosatisfactivas. IUS ET VERITAS 15.

Rodríguez-Patrón, P. (2001) La libertad del Tribunal Constitucional alemán en la configuración de su derecho procesal. Revista Española de derecho constitucional 62 .

Sagüés, N. (2010). Obligaciones internacionales y control de convencionalidad. Estudios constitucionales 8.1.

Valadés, D. (2011). "La protección de los derechos fundamentales frente a particulares”. Anuario de Derechos Humanos. Nueva Época 12.

Valle, A. (2012). El amparo como garantía constitucional en el Ecuador. Quito: UASB, Corporación Editora Nacional.

\section{Jurisprudencia Constitucional}

Corte Constitucional del Ecuador para el periodo de transición. Sentencia No. 068-10-SEP-CC, Caso No. 0734-09-EP de 09 de diciembre de 2010. Juez ponente: Manuel Viteri Olvera. 
Corte Constitucional del Ecuador para el periodo de transición. Sentencia No. 052-11-SEP-CC, Caso No. 0502-11-EP de 15 de diciembre 12 de 2011. Juez ponente: Roberto Bhrunis Lemarie

Corte Constitucional del Ecuador para el periodo de transición. Sentencia No. 001-11-SCN-CC, Caso No. 0031-10-CN y acumulados, de 11 de enero 2011. Juez ponente: Patricio Pazmiño Freire.

Corte Constitucional del Ecuador. Sentencia No. 026-14-SIS-CC, Caso No. 0041-11-IS de 13 de noviembre de 2014. Juez ponente: Antonio Gagliardo Loor.

Corte Constitucional del Ecuador. Sentencia No. 045-15-SIS-CC, Caso No. 0095-11-IS de 09 de julio de 2015. Juez ponente: Fabián Jaramillo Villa.

Corte Constitucional del Ecuador. Sentencia No. 226-15-SEP-CC, Caso No. 1344-11-EP, de 15 de julio de 2015. Jueza ponente: Tatiana Ordeñana Sierra.

Corte Constitucional del Ecuador. Sentencia No. 261-15-SEP-CC, Caso No. 0383-13-EP, de 12 de agosto de 2015. Jueza ponente: María del Carmen Maldonado Sánchez.

Corte Constitucional del Ecuador. Sentencia No. 037-16-SEP-CC, Caso No. 0977-14-EP de 3 de febrero de 2016. Juez ponente: Patricio Pazmiño Freire.

Corte Constitucional del Ecuador. Sentencia No. 364-16-SEP-CC, Caso No. 1470-14-EP de 15 de noviembre de 2016. Jueza ponente: Tatiana Ordeñana Sierra.

Corte Constitucional del Ecuador. Sentencia No. 002-17-SIN-CC, Caso No. 0021-11-IN de 08 de febrero de 2017. Jueza ponente: Marien Segura Reascos.

Corte Constitucional del Ecuador. Sentencia No. 032-17-S1S-CC, Caso No. 0106-11-IS de 2 de agosto de 2017. Jueza ponente: Pamela Martínez Loayza. 
Corte Constitucional del Ecuador. Sentencia No. 040-17-SIS-CC, Caso No. 0044-16-IS de 23 de agosto de 2017. Jueza ponente: Wendy Molina Andrade.

Corte Constitucional del Ecuador. Sentencia No. 004-18-SIS-CC, Caso No. 0032-14-IS de 07 de febrero 02 de 2018. Jueza ponente: Ruth Seni Pinoargote.

Corte Constitucional del Ecuador. Sentencia No. 23-13-IS/19, Caso No. 2313-IS de 20 de agosto de 2019. Jueza ponente: Karla Andrade Quevedo.

Corte Constitucional del Ecuador. Sentencia No. 154-12-EP/19, Caso No. 154-12-EP de 20 de agosto de 2019. Jueza ponente: Daniela Salazar Marín

Corte Constitucional del Ecuador. Sentencia No. 66-15-JC/19, Caso No. 6615-JC de 10 de septiembre de 2019. Juez ponente: Ramiro Ávila Santamaría.

Corte Constitucional del Ecuador. Sentencia No. 2453-16-EP/19, Caso No. 2453-16-EP, de 02 de octubre de 2019. Juez ponente: Agustín Grijalva Jiménez.

Corte Constitucional del Ecuador. Sentencia No. 1-12-IS/19, Caso No. 1-12IS de 23 de noviembre de 2019. Juez ponente: Agustín Grijalva Jiménez.

Corte Constitucional del Ecuador. Sentencia No. 1589-13-EP/19, Caso No. 1589-13-EP, de 28 de octubre de 2019. Jueza ponente: Teresa Nuques Martínez. 